\title{
SONG STRUCTURE, BEHAVIOUR, AND SEQUENCE OF SONG TYPES IN A POPULATION OF VILLAGE INDIGOBIRDS, VIDUA CHAL YBEATA
}

\author{
BY ROBERT B. PAYNE \\ Museum of Zoology and Division of Biological Sciences, The University of Michigan, Ann Arbor, \\ Michigan 48109
}

\begin{abstract}
Different song types are associated with certain behaviours including intrasexual aggression, mating, and initiation of song bouts. All song types are used in territorial advertisement. Songs associated with sexual and aggressive behaviours are similar in structure; female mate choice may have driven sexual selection in favour of the more aggressive males. Song sequence is non-random with repetition of all song types and alternation of some, and songs with similar messages are often associated in sequence. Predictions from alternative models were tested, but the significance of the large song repertoire in this species is largely explained by the message content of the different song types.
\end{abstract}

The biological significance of bird songs usually has been attributed to male territorial advertisement and attraction of a mate. The significance of the number of songs, or of having more than one song type in the song repertoire, often has been discussed in terms of territorial interaction among males or mate selection by females as if all song types were functionally identical. Krebs (1977) summarized the arguments for the possible adaptive significance of large song repertoire in deterring other males (countersinging, avoiding habituation by neighbours, and deterring new settlers by a 'Beau Geste' effect), and Howard (1974) and Kroodsma (1976a, 1976b, 1977) suggested that males with large song repertoires are more successful in attracting females. An alternative explanation of a song repertoire is that different songs may communicate different behavioural 'messages' (Smith 1977). In a few birds with a small number of songs (two to eight song types), different songs are associated statistically with different behaviours (Smith 1959; Immelmann 1968; Smith 1969, 1977; Morse 1970; Thielcke 1970; Thielcke \& Thielcke 1970; Lein 1972, 1978; Baptista 1978). The time required to sample behaviour associations with song types in a bird with a large repertoire has limited the observational study of the function of a bird song. The circumstances of singing may suggest a common behavioural message for many song types (Verner 1976), but generally, lack of study rather than any contrary empirical data or theoretical reasons have led us to think that songs within a species generally carry the same message.

These hypotheses of the significance of song repertoire size were tested in village indigobirds, Vidua chalybeata, an African finch with a large song repertoire. In this species individual differences among males in the amount of song are related to success in male territorial advertisement, attracting females, and mating. Indigobirds are highly polygynous brood-parasites whose young are reared by the red-billed firefinch Lagonosticta senegala. Indigobirds mimic the songs of the firefinch hosts and also sing a number of non-mimetic songs that are shared among neighbours but that differ among local populations (Payne 1973; Payne \& Payne 1977). Birds in a local song population were observed to test whether different song types were associated with different behaviours and hence had different behavioural messages. Structure and sequence of songs were examined to find whether these supported a motivational or message model of song diversity. In addition, several predictions from the female attraction and male territorial advertisement hypotheses of large song repertoires were tested by field observations.

\section{Methods}

Indigobirds were observed and tape-recorded at Lochinvar National Park, Zambia, at $15^{\circ} 50^{\prime} \mathrm{S}$, $27^{\circ} 15^{\prime} \mathrm{E}$, during the breeding seasons from 1972 to 1976. Males sing at traditional call-sites (Payne 1973; Payne \& Payne 1977); most birds were individually marked with coloured leg rings. Samples of at least 100 successive songs were recorded for most males, using a Nagra IV-D tape recorder at $19 \mathrm{~cm} / \mathrm{s}$ and Sennheiser MKH 805 directional microphone, or a Uher $4000-\mathrm{L}$ tape recorder at $9.5 \mathrm{~cm} / \mathrm{s}$ and Uher M-515, 516, or 517 microphone with parabolic reflector. Recorded songs were later analysed with a Kay Elemetrics 'Vibralyzer' $7030 \mathrm{~A}$ using wide-band setting. Song types were identified from the audiospectrograms. 
Individual singing males were observed and recorded with a focal-animal sampling technique (Altmann 1974; Payne \& Payne 1977). Behaviour was noted with accompanying song on the recording tape as it occurred in the field. Behaviour included aggressive interactions among males, sexual interactions, comfort movements, and beginnings and endings of singing bouts. Tapes were later played and all song types immediately before or after a behavioural act were analysed and identified. Aggressive and sexual interactions were always reported when seen, but comfort movements and changes in singing behaviour were only sometimes reported when they occurred. The sampling differences were due to some observers in some years noting only the aggressive and sexual behaviours, whereas in other years we reported all instances of all behaviours. Behaviours were thus sampled in an unbiased manner with respect to song type. To test whether the song types and behaviours are independent, an overall test was applied to songs with large numbers of behaviour observations. The overall test used was the log likelihood ratio test (G-test of Sokal \& Rohlf 1969). Individual behaviours were then tested for differences among song types in the proportion of observed behaviours to the proportion expected from the overall frequencies of the song types associated with each behaviour, using the simultaneous confidence interval test of Goodman (1964).

A transition matrix was constructed to describe the first-order sequence of song types in a sample recorded and identified from 1972 to 1974. Tests of independence among all song types were made with the log likelihood ratio test, and tests of individual song associations were made using the simultaneous confidenceinterval test.

To compare the similarity of the different song types in a test of the significance of song structure in songs associated in sequence, notes on the audiospectrograms were categorized and measured, and a series of song characters was used to compute an overall index of similarity among the song types. Similarity coefficients were computed using the product-moment correlation coefficients $\left(r_{\mathrm{p}}\right)$, with standardized transformations of the song characters. A matrix of phenetic distances was constructed, where the distance $D=1-r_{\mathrm{p}}$ was computed to summarize the overall differences among the song types. The technique is described in Sneath \& Sokal (1973). Phenetic distances were then compared between regularly sequential song types and the other dyads of song types. Individual song-character differences were compared in a similar way using a Mann-Whitney $U$-test of rank order.

\section{Song Structure}

\section{Results}

Indigobird songs are stereotyped sequences of buzzy notes and whistled notes. I refer to the sequence of notes as 'songs' because the sequences are structurally complex. Bird calls, on the other hand, are single notes or a series of similar simple notes. Song types are distinct and are categorized by the sequence and timing of the characteristic notes, as shown in Fig. 1. Except for simple chatter notes and for mimetic alarm notes, the notes are generally unique to each song type. A male sings the notes in the same sequence and timing with remarkable consistency. Variations occur but usually involve simply the addition or deletion of some introductory notes or the deletion of terminal notes. All 14 birds in the local area shared all or nearly all of the song types (Table I). Where a song type is missing for a bird in Table $I$, the sample of songs recorded may have been too small to include the complete repertoire. Some birds also sang two song types $(20,21)$ unique to

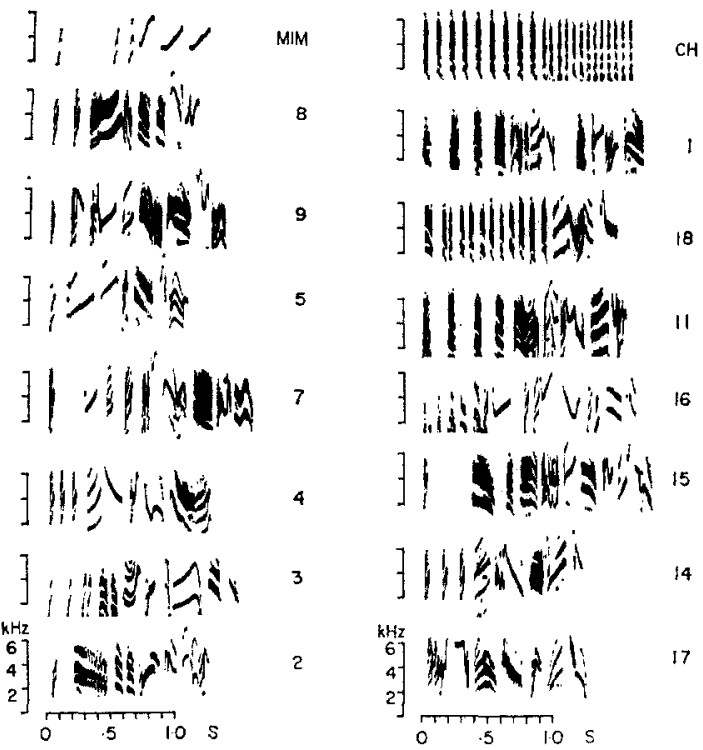

Fig. 1. Song types recorded from indigobird RYRB on the Junction call-site at Lochinvar Park in 1973. MIM $=$ mimicry, $\mathrm{CH}=$ chatter, numbers refer to the song type number. 
Table I. Song Sharing in a Local Population (Junction) of Village Indigobirds in Lochinvar National Park Zambia, in 1973*

Number of songs of each song type

\begin{tabular}{lrrrrrrrrrrrrrrrrr} 
Bird & Chatter & 1 & 18 & 11 & Mimicry & 16 & 15 & 14 & 17 & 8 & 9 & 5 & 7 & 4 & 3 & 2 & Total \\
\hline YGRY & 10 & 0 & 14 & 0 & 15 & 2 & 4 & 4 & 3 & 2 & 2 & 13 & 15 & 1 & 9 & 4 & $100 \dagger$ \\
RYYB & 12 & 17 & 14 & 0 & 23 & 9 & 7 & 11 & 11 & 18 & 13 & 17 & 13 & 20 & 14 & 10 & 209 \\
RGYB & 0 & 0 & 6 & 1 & 14 & 1 & 3 & 1 & 1 & 0 & 1 & 2 & 1 & 1 & 2 & 1 & 35 \\
RBRG & 25 & 11 & 11 & 9 & 52 & 5 & 14 & 5 & 2 & 7 & 12 & 6 & 6 & 7 & 12 & 8 & $202 \ddagger$ \\
SEBZ & 1 & 0 & 1 & 0 & 1 & 0 & 0 & 2 & 2 & 4 & 5 & 4 & 7 & 4 & 0 & 0 & 31 \\
RBGY & 10 & 1 & 13 & 7 & 26 & 3 & 10 & 12 & 7 & 6 & 7 & 6 & 5 & 6 & 6 & 6 & 137 \\
RYBR & 5 & 0 & 11 & 3 & 20 & 7 & 9 & 7 & 7 & 4 & 3 & 10 & 12 & 7 & 7 & 6 & 118 \\
FHYW & 15 & 0 & 8 & 2 & 13 & 1 & 5 & 6 & 6 & 3 & 5 & 4 & 0 & 2 & 3 & 2 & 75 \\
RYYG & 38 & 2 & 34 & 12 & 76 & 26 & 23 & 31 & 21 & 35 & 44 & 36 & 36 & 34 & 26 & 22 & 496 \\
YGRB & 17 & 1 & 15 & 10 & 52 & 10 & 23 & 18 & 10 & 26 & 19 & 19 & 22 & 20 & 13 & 10 & 285 \\
RYRB & 41 & 5 & 42 & 18 & 102 & 14 & 30 & 25 & 28 & 21 & 30 & 56 & 41 & 39 & 29 & 19 & 540 \\
YGYB & 0 & 0 & 0 & 0 & 11 & 3 & 0 & 5 & 5 & 4 & 2 & 5 & 4 & 3 & 5 & 4 & 51 \\
RGRG & 11 & 11 & 0 & 9 & 24 & 5 & 12 & 11 & 7 & 13 & 15 & 7 & 12 & 5 & 7 & 7 & 156 \\
RYYR & 5 & 2 & 7 & 1 & 9 & 2 & 9 & 0 & 0 & 1 & 3 & 7 & 0 & 8 & 4 & 3 & 61 \\
\hline
\end{tabular}

"Excluded here and elsewhere in this paper are two uncommon song types $(20,21)$ for which no context events were recorded.

†Bird also sang song types characteristic of the song population south of the park (cowpie dialect area).

$\ddagger$ Bird also sang song types characteristic of the song population east of the park (diptera dialect area).

the local population, but these data are deleted as too few associations of behaviour and song sequences were available for statistical analysis. Neighbouring males shared a song type with almost no variation among birds (Fig. 2). Songs of RYRB, the male with the highest mating success in 1973, were measured for structural characters. Populations south, east, and west of the one described here also had unique songs, with no notes of any songs matching those of this local population or of each other, except for the simple chatter noises and mimetic notes that are shared among populations. Each local song type changed slightly from year to year in certain notes, and the changes in these notes accumulated over the years, but song types can readily be matched across successive years, and the 1973 songs are representative.

Songs vary also in more general characteristics such as duration, number of notes, and proportions of buzzy, chattery notes and whistled notes, many of which are acoustically identical to those recorded from the host firefinch species (Payne 1973). Song features were determined from audiospectrograms. Frequency ranges of notes were not used because of difficulties in determining faint traces in the extreme high and low ranges, because of complications of overtones, and because visual inspection of songs showed no obvious differences among songs in the frequency ranges.

Notes were classified as either whistles or modulated. Notes were termed whistles if they lacked rapid frequent changes in pitch and were apparently delivered in a continuous pulse, either constant in rate of change in pitch with a continuous rise or fall, or changing once or a few times in pitch. Notes were termed modulated if they appeared to be delivered with pulses or if they covered a wide frequency band and the rate of change of pitch exceeded 10 inflections per $100 \mathrm{~ms}$. Marler (1969) has discussed the difficulties involved in categorizing modulated sounds. The classification used here is a rough attempt to separate notes in a way 


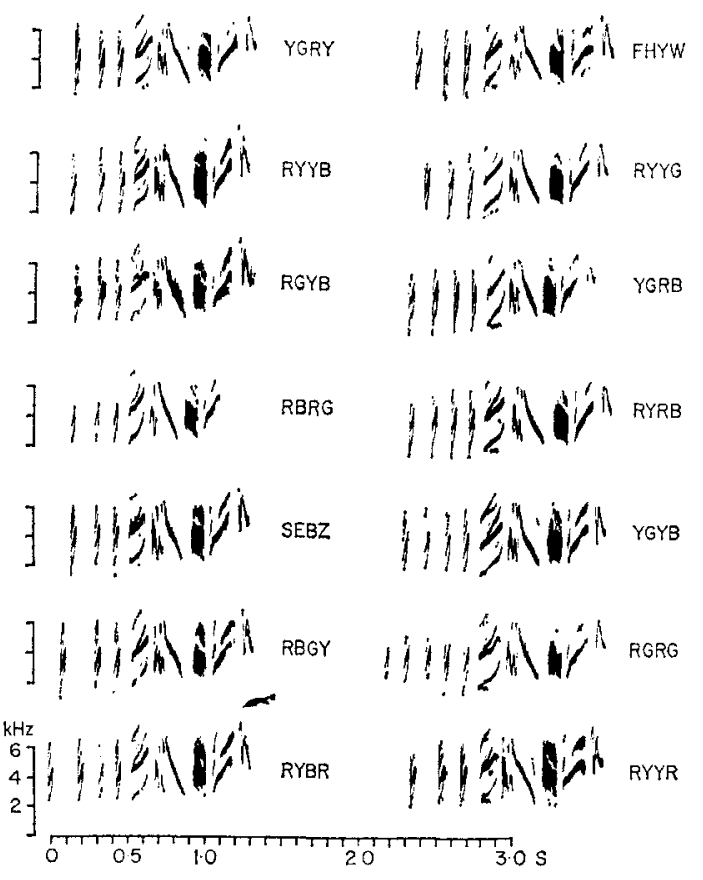

Fig. 2. Examples of song type 14 as sung by 14 different individual male indigobirds in 1973. Letters refer to the colour rings for each bird, except FHYW, a mottled unmarked bird at FHYW call-site, and SEBZ, a male in breeding plumage at Sebanzi call-site. Note the close match among all local males. Male RBRG typically had a simpler note 5 than did the other males; he sometimes included the last note like that of the other males. The song type is representative of the degree of song sharing among males for all song types in the local population.

consistent with their whistled versus buzzy sounds. Examination of the audiospectrograms shows that structure of notes intergrades (notes 4 and 5 in song 15 , both called modulated; note types 1 (repeated four times), 2, 3, and 6 in song 11, the first two modulated and the second two whistles of rapidly changing pitch). Note types assigned in song type 3 shown in Fig. 1 illustrate the remaining details. The first four notes are mimetic alarm notes, the next two are chatter (modulated), the next (the third type of note, so note 3 in the note sequence) is a modulated note, note 4 is partly mimetic alarm and partly a whistle, notes 5 and 6 are whistles, 7 is a modulated note (close inspection of the original audiospectrogram shows a zigzag boundary along the upper and lower boundary in the note), and 8 is a whistle. Characters were measured for the first six notes because some song types (mimicry) had only six notes.

Table II summarizes the song type characteristics of the Junction dialect area in 1973. Songs range from 0.9 to $1.7 \mathrm{~s}$ in duration and are composed of 2 to 11 different kinds of notes. In song characters 1 and 3 , only the first 10 chatter notes were counted as in songs with more than 10 chatter notes, the number varied in successive songs. Not included in Table II are single chatter notes, or short versions of song type 1 given off the call-site as the male chased other males. Also excluded are variants of song mimicry of the firefinch host species other than the most commonly heard variant of song; other mimetic vocalizations of adult male indigobirds include other variants of song, alarm notes, juvenile contact notes, and nestling and fledgling begging notes (Payne 1973). Table II does not describe the most distinctive features of songs, which are the characteristic shapes of each note and the precise temporal sequencing of notes within each song type. Chatter is distinctive in being composed usually of a single kind of note repeated many times, though some chatter sequences as in Fig. 1 had two kinds of notes. Other song types had at least four kinds of notes.

\section{Behaviour Associated with the Song Types}

The functional significance of signals such as bird song is most readily determined through behaviour changes of the performing individual that were associated with its signals. Two complementary approaches to the study of function are (1) motivational or causational analysis, where different behaviours ascribed to a smaller set of underlying tendencies to perform sexual, aggressive, or other functional classes of behaviour, are associated with each song (Tinbergen 1959; Hinde 1970) and (2) message analysis, where specific acts themselves are associated with the songs, rather than with assumed common motivational factors (Smith 1977). Behavioural analysis of the indigobird songs was made by comparing the behaviour changes that accompanied each song type. Singing males usually sing for many minutes continuously without changing behaviour, and this prolonged singing is regarded as territorial advertisement behaviour. In the present analysis, behaviours other than simply singing another song in a continuing sequence were used as criteria to define the messages of song other than territorial advertisement. Ten mutually exclusive 
Table II. Description of Structural Characters of 16 Song Types in a Population of Indigobirds

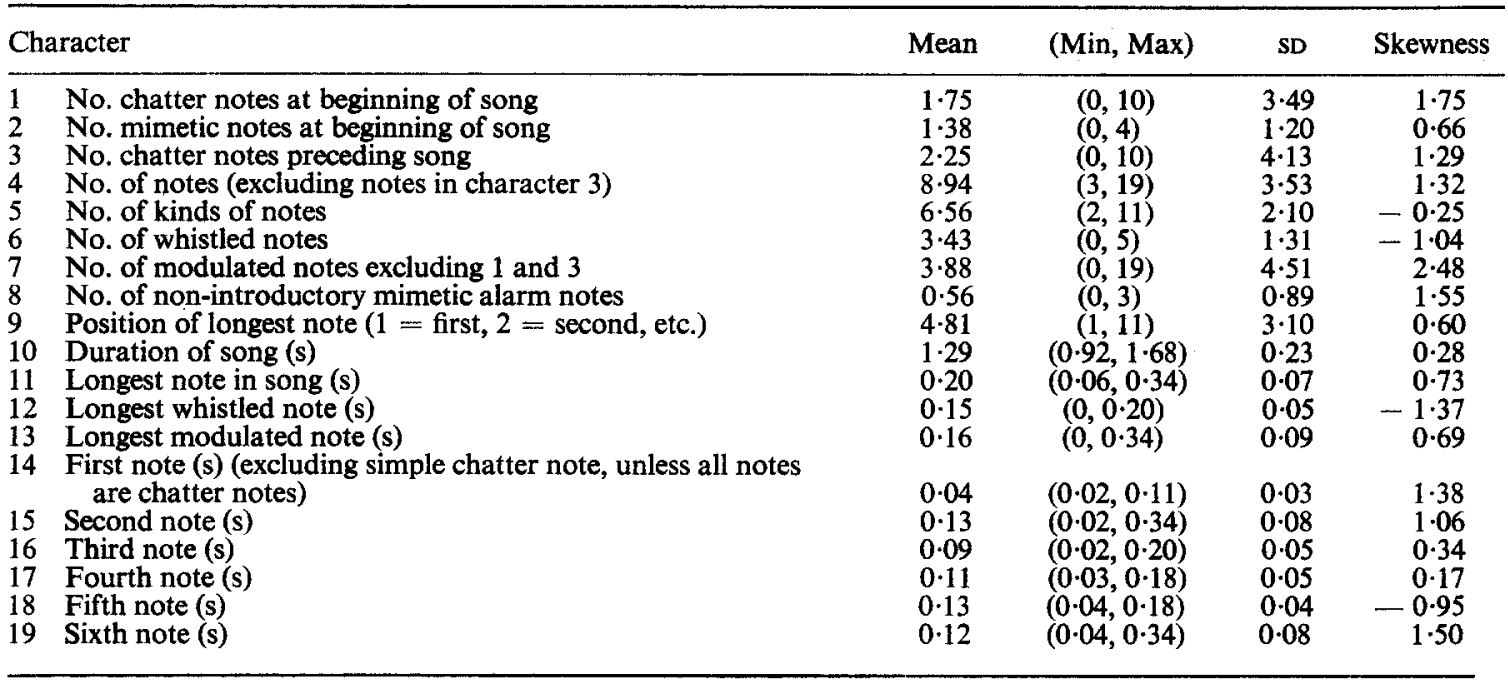

classes of behaviour were used, as described below. Other behaviours were observed but were deleted as unsuited for quantitative comparison among songs if fewer than 10 instances were noted. Behaviours that occurred within $10 \mathrm{~s}$ of the song were considered to be associated with the song, except where a different time criterion is noted.

1. Chase. A male flew from the call-site toward another male perched visibly within $100 \mathrm{~m}$ of the site, toward a male flying over the area, or toward a male not seen by the observer but presumed to be nearby, because the male flew in a rapid zigzag typical of most chases toward visible males, but not of flights to feeding areas or visiting flights to neighbouring call-sites (Payne \& Payne 1977).

2. Flew. A male flew from the call-site (usually to feed, drink, or visit neighbours on their callsites) but not with zigzag flight and not toward another male or a female seen by the observer. A few flights may have been aggressive flights toward other males or flights to females.

3. Female visits call-site. Most visits of females to the call-site were preceded by bouts of song by the male, and the last song given before the female perched on the site was regarded as associated with the visit.

4. Courtship display. In courtship, the male hovered over the female as she perched on the call-site (Payne 1973; Payne \& Payne 1977). Song during display (often accompanied on tape recordings by faint wingflaps) was considered associated with the display; only one song was ever given during a display.

5. End song bout. The last song in a bout of at least 10 songs in a $2-$ min period, followed by a pause of $20+s$ of silence of the bird on the call-site.

6. Begin song bout. The first song in a bout of at least five songs in a 2 -min period, when preceded by a period of silence on the call-site of $20+\mathrm{s}$.

7. Comfort movement. Male preened, stretched, scratched, wiped bill on perch, or changed perch by turning around, hopping along the same branch, or hopping or flying to another branch. In bouts of bill wiping and comfort movements, only one movement was counted for a song, for example the last song before a bill wipe and the first song after a bill wipe. Bouts of comfort movements sometimes persisted a minute or two; bouts were regarded as separate if no comfort movements occurred for $20 \mathrm{~s}$ between acts.

8. Return after chase. Male returned to callsite after chasing another male and sang within $20 \mathrm{~s}$ of his return.

9. Return, no chase. Male returned to call-site after some activity other than a chase. However I may have erroneously included returns after some chases, as only in about half the instances the males were seen to be feeding or drinking. 
10. Postcourtship display. Following a courtship display over a female perched on the site, the male often sang either perched on the callsite or (more often observed to occur, but less frequently tape-recorded) from the ground, where he was often followed by the female who then fed with him. The first song given within $5 \mathrm{~s}$ after a display was considered to be associated with the display.

Songs that precede a behaviour may signal the tendency of the bird to perform the act, such as an aggressive act (1), may indicate a certain motivational state of the bird, or may give a message that the bird will attack. Songs given after acts may also be associated with internal motivational conditions in the sense of an internal state persisting, but may not predict the subsequent behaviour. In principle one may test whether the 'message' model of Smith (1977) is simply a special case of the 'motivational' model of classical ethologists by determining whether the same behaviours are associated with a song type both before and after the song type. The 'message' model predicts an association of a song type only before a behaviour, whereas the 'motivational' model predicts associations both before and after.

Observations of songs associated with behaviour were analysed for 1972 to 1974. Data are pooled for all 14 birds observed. All birds appeared to use the same song types in the same situations, at least when the behaviours were observed. Except for behaviour (3), other birds apparently did not respond to individual songs, and inference about the communicatory function of the song types is therefore based on changes in behaviour of the singing male, and not based on observed changes in behaviour of birds other than the singing male.

All song types were given by males in prolonged bouts of singing on the call-site during which the bird otherwise did not change behaviour (Table III). Males with higher song rates and with more minutes of singing per hour attract more females, get more matings, and are more successful in defending the best call-sites from other males (Payne \& Payne 1977). Each song type probably functions in part to advertise the presence of the singing male and his continuing likelihood to attack if another male enters his area. Certain song types nevertheless were associated with changes in the behaviour of the male more often than other song types. The frequency with which the song types were associated with any behaviour transitions differs significantly among song types (Table III, $\log$ likelihood ratio test $\chi^{2}=976.9, d f=15$, $P<0.0001$ ).

Most song types were given at least occasionally before changes to a variety of different mutually exclusive behaviours (Table IV). The low proportion of songs that were accompanied by a change in behaviour (Tables III, IV) defines a low syntactical 'information' value for songs, but this outcome is not unusual in animal communication. The message of a signal may be modified by local behavioural circumstances (Smith 1977), and varying circumstances between different periods of singing may account in part for the low apparent information value of the songs. In addition, behaviours may occur without the song that sometimes signals them if circumstances demand rapid activity of the singing male. For example, two song types (1 and chatter, discussed below) are often associated with male-male chases, but not always, and field observations showed that the male gave these songs in his prolonged territorial advertisement singing as well as in chase (two circumstances) and he also sometimes chased off an intruding male as soon as he saw the intruder, simply breaking off his singing at any song without first giving his song types 1 or chatter (immediate action not preceded by a defined message).

Table III. Number of Songs and Associated Behaviours Recorded for 16 Song Types in a Population of Village Indigobinds

\begin{tabular}{cccc}
\hline Song type & $\begin{array}{c}\text { No. songs } \\
\text { recorded } \\
\text { without } \\
\text { behaviour }\end{array}$ & $\begin{array}{c}\text { No. songs } \\
\text { with } \\
\text { behaviour, } \\
\text { before or } \\
\text { after song }\end{array}$ & $\begin{array}{c}\text { \% songs } \\
\text { with } \\
\text { behaviour }\end{array}$ \\
\hline CH & 856 & 364 & 30 \\
1 & 247 & 147 & 37 \\
18 & 464 & 107 & 19 \\
11 & 342 & 92 & 21 \\
MIM & 2077 & 130 & 6 \\
16 & 221 & 14 & 6 \\
15 & 522 & 33 & 6 \\
14 & 397 & 86 & 6 \\
17 & 324 & 28 & 8 \\
8 & 556 & 28 & 5 \\
9 & 698 & 23 & 3 \\
5 & 597 & 51 & 8 \\
7 & 559 & 31 & 5 \\
4 & 572 & 25 & 4 \\
3 & 522 & 12 & 1 \\
2 & 377 & 2 & \\
Total & 9331 & 1173 & \\
\hline
\end{tabular}


The data of Table IV are too few to apply an overall test for independence of all types and all behaviours. Statistical comparison was therefore restricted to the song types for which the sum of associated behaviours was at least 28 . The proportions of behaviours associated with each of these song types are given in Table $\mathrm{V}$. Table $V$ shows a significant departure from independence of song type and associated behaviours (log likelihood ratio test $\chi^{2}=203 \cdot 48, d f$ $=30, P<0.001)$. The results indicate that these different song types differ in the proportions of behaviours that follow the song. Hence the song types may code different behavioural messages.

Songs were also given after certain behaviours (Table VI). The small number of observations here disallows an overall statistical test for independence of all song types and all behaviours. Table VII lists for each cell, the percentage of row total (song type) that occurs in the cell, i.e. the distribution of behaviours associated with each song type for which at least 28 songbehavioural transitions were observed. Table VII as a whole shows a significant departure from independence of song type and associated behaviour (log likelihood ratio test $\chi^{2}=96.48, d f=15, P<$ 0.005 for each test). For these six song types, the likelihood of song being given after an observed behaviour varies significantly among song types.

As Tables V and VII each show a statistically significant departure from independence of song type and behaviour, the individual song types

Table IV. Behaviour to Which Male Changed after Each Song Type

\begin{tabular}{|c|c|c|c|c|c|c|c|c|}
\hline \multirow[b]{2}{*}{ Song type } & \multicolumn{8}{|c|}{ Behaviour } \\
\hline & $\begin{array}{l}\text { Flew in } \\
\text { chase }\end{array}$ & Flew & $\underset{\text { in }}{\text { Female }}$ & $\begin{array}{l}\text { Courtship } \\
\text { display }\end{array}$ & $\begin{array}{c}\text { End song } \\
\text { bout }\end{array}$ & $\begin{array}{l}\text { Begin song } \\
\text { bout }\end{array}$ & $\begin{array}{c}\text { Comfort } \\
\text { movements }\end{array}$ & Total \\
\hline Chatter & 31 & 42 & 15 & 0 & 1 & 48 & 73 & 210 \\
\hline 1 & 9 & 10 & 4 & 0 & 1 & 20 & 22 & 66 \\
\hline 18 & 3 & 11 & 14 & 0 & 3 & 4 & 33 & 68 \\
\hline 11 & 0 & 4 & 13 & 22 & 3 & 0 & 22 & 64 \\
\hline Mimicry & 3 & 10 & 0 & 0 & 0 & 0 & 2 & 15 \\
\hline 16 & 0 & 1 & 0 & 0 & 0 & 5 & 2 & 8 \\
\hline 15 & 0 & 3 & 0 & 0 & 2 & 5 & 8 & 18 \\
\hline 14 & 1 & 2 & 4 & 0 & 0 & 12 & 11 & 30 \\
\hline 17 & 0 & 1 & 2 & 0 & 0 & 6 & 2 & 11 \\
\hline 8 & 1 & 6 & 0 & 0 & 1 & 2 & 10 & 20 \\
\hline 9 & 0 & 6 & 0 & 0 & 1 & 1 & 13 & 21 \\
\hline 7 & 0 & 6 & 0 & 0 & 1 & 1 & 14 & 22 \\
\hline 5 & 0 & 6 & 0 & 0 & 1 & 4 & 18 & 29 \\
\hline 4 & 0 & 3 & 0 & 0 & $i$ & 1 & 16 & 21 \\
\hline 3 & 0 & 0 & 0 & $\mathbf{0}$ & 0 & 0 & 11 & 11 \\
\hline 2 & 0 & 0 & 0 & 0 & 0 & 0 & 2 & 2 \\
\hline Total & 48 & 111 & 52 & 22 & 15 & 109 & 259 & 616 \\
\hline
\end{tabular}

Table V. Behaviour to which Male Changed after Each Song Type (\%)*

\begin{tabular}{lccccccc}
\hline & \multicolumn{7}{c}{ Behaviour } \\
\cline { 2 - 8 } Song type & $\begin{array}{c}\text { Flew in } \\
\text { chase }\end{array}$ & Flew & $\begin{array}{c}\text { Female } \\
\text { in }\end{array}$ & $\begin{array}{c}\text { Courtship } \\
\text { display }\end{array}$ & $\begin{array}{c}\text { End song } \\
\text { bout }\end{array}$ & $\begin{array}{c}\text { Begin song } \\
\text { bout }\end{array}$ & $\begin{array}{c}\text { Comfort } \\
\text { movements }\end{array}$ \\
\hline Chatter & $14 \cdot 76^{*} \dagger$ & $20 \cdot 00$ & $7 \cdot 14$ & 0 & $0 \cdot 48$ & $22 \cdot 86 \dagger$ & $34 \cdot 76$ \\
1 & $13 \cdot 64$ & $15 \cdot 15$ & 6.06 & 0 & $1 \cdot 51$ & $30 \cdot 30 \dagger$ & $33 \cdot 33$ \\
18 & $4 \cdot 41$ & $16 \cdot 18$ & $20 \cdot 59$ & 0 & 4.41 & $5 \cdot 88$ & $48 \cdot 53$ \\
11 & 0 & 6.25 & $20 \cdot 31$ & $34 \cdot 37 \dagger$ & $4 \cdot 69$ & 0 & 34.37 \\
14 & $3 \cdot 33$ & 6.67 & $12 \cdot 33$ & 0 & 0 & $40 \cdot 00 \dagger$ & $36 \cdot 67$ \\
5 & 0 & 20.69 & 0 & 0 & 3.45 & $13 \cdot 79$ & 62.07
\end{tabular}

*Includes only song types with at least 28 observations of behaviour from Table IV. Percentage of each subsequent behaviour is calculated separately for each song type.

†Indicates that the behaviour for the row song type was significantly higher than at least one other song type in the table $(P<0.05$, Goodman's simultaneous confidence intervals test $)$, see text for details. 
A N IMAL BEHAVIOUR, 27, 4

Table VI. Behaviour Male Gave before Each Song Type

\begin{tabular}{lccccr}
\hline Song type & \multicolumn{5}{c}{ Behaviour } \\
\cline { 2 - 6 } & $\begin{array}{c}\text { Return after } \\
\text { chase }\end{array}$ & $\begin{array}{c}\text { Return, no } \\
\text { chase }\end{array}$ & $\begin{array}{c}\text { Courtship } \\
\text { display }\end{array}$ & $\begin{array}{c}\text { Comfort } \\
\text { movements }\end{array}$ & Total \\
\hline Chatter & 30 & 62 & 8 & 54 & 154 \\
1 & 19 & 22 & 9 & 31 & 81 \\
18 & 1 & 4 & 1 & 33 & 39 \\
11 & 0 & 2 & 7 & 19 & 28 \\
Mimicry & 6 & 37 & 14 & 58 & 115 \\
16 & 1 & 3 & 2 & 0 & 6 \\
15 & 0 & 5 & 4 & 6 & 15 \\
14 & 2 & 24 & 0 & 30 & 56 \\
17 & 1 & 15 & 1 & 0 & 17 \\
8 & 0 & 2 & 0 & 6 & 2 \\
9 & 0 & 2 & 0 & 0 & 9 \\
7 & 0 & 0 & 0 & 9 & 22 \\
5 & 0 & 6 & 0 & 16 & 1 \\
4 & 0 & 4 & 0 & 0 & 0 \\
3 & 0 & 1 & 0 & 0 & 557 \\
2 & 0 & 0 & 0 & 0 & 262 \\
Total & 60 & 189 & 46 & 262 & \\
\hline
\end{tabular}

Table VII. Behaviour Male Gave before Each Song Type (\%)*

\begin{tabular}{|c|c|c|c|c|}
\hline \multirow[b]{2}{*}{ Song type } & \multicolumn{4}{|c|}{ Behaviour $(\%)$} \\
\hline & $\begin{array}{l}\text { Return after } \\
\text { chase }\end{array}$ & $\begin{array}{l}\text { Return, } \\
\text { no chase }\end{array}$ & $\begin{array}{l}\text { Courtship } \\
\text { display }\end{array}$ & $\begin{array}{l}\text { Comfort } \\
\text { movements }\end{array}$ \\
\hline $\begin{array}{l}\text { Chatter } \\
1 \\
18 \\
11 \\
\text { Mimicry } \\
14\end{array}$ & $\begin{array}{c}19 \cdot 48 \dagger \\
23 \cdot 48 \dagger \\
2 \cdot 56 \\
0 \\
5 \cdot 22 \\
3 \cdot 57\end{array}$ & $\begin{array}{l}40 \cdot 26 \dagger \\
27 \cdot 16 \\
10 \cdot 26 \\
7 \cdot 14 \\
32 \cdot 17 \dagger \\
42 \cdot 86 \dagger\end{array}$ & $\begin{array}{r}5 \cdot 20 \\
11 \cdot 11 \\
2 \cdot 56 \\
25 \cdot 00 \\
12 \cdot 17 \\
0\end{array}$ & $\begin{array}{l}35.06 \\
38.27 \\
84 \cdot 62 \uparrow \\
67 \cdot 86 \uparrow \\
50 \cdot 43 \\
53 \cdot 57\end{array}$ \\
\hline
\end{tabular}

were compared within each table. Using 95\% simultaneous confidence levels (Goodman 1964) for all simultaneous pairwise comparisons within a behaviour category, the confidence interval tests showed the following significant differences among the song types.

Aggressive behaviour (male flew in chase) occurred proportionally more often after chatter than after song type 11 . Other comparisons among song types showed no statistically significant differences. In Table $\mathrm{V}$, aggressive behaviour was given nearly as often after song type 1 as after chatter, but the statistical test did not confirm the association of song type 1 and chase. The other aggressive behaviour observed was the return to the call-site at the end of a chase. Both chatter and song type 1 were given significantly more often than were the other song types in Table VII after this behaviour. Not recorded in the tables because they occurred off the call-site were other observations of birds singing while actually chasing other males; all instances of song during chase were of chatter and of song type 1 , usually a short version that lacked the last notes. Males also gave these two song types, and no others, when 
they supplanted other visiting males in their call-site tree. The results show that song type 1 and chatter are associated with aggressive behaviour of males toward other males.

Flying from the call-site was not significantly associated with one song type more than another; Table $\mathrm{V}$ shows that four song types were given in about the same proportion in this situation. Returning to the call-site with no chase was associated with some significant differences among song types. A male was significantly more likely to give chatter, song type 14 , or mimicry upon return to the site than it was to give song types 18 or 11 (Table VII). Some flights may have involved chases, and this may explain the incidence of chatter. The results show no one 'sign-off' song type for a male about to fly from a site, but certain songs tend to be given upon return to the site.

When a female flew to the call-site, it tended to be when the male gave song type 18 or 11 (Table V). In the field, females appeared to fly to the site particularly when the male sang song type 18. Males often sang several 18's in series, crouching, looking around, then facing the female if one flew toward the site. However, the simultaneous confidence-interval test showed no significant differences among song types. Table III shows that several song types were given more often than 18 or 11 , and Table IV shows that most of these were not given when a female visited the call-site. The apparent non-significance of the association probably results from the small sample size of songs and associated behaviour. In courtship display, which preceded the attempt of the male to mount the female, the only song given was song type 11 . Males were silent in 14 of 36 observed courtship displays. The simultaneous confidence-interval test showed a significant association of courtship display and song type 11 . The male was silent in all courtship sequences that led successfully to copulation, and he sang only in attempted copulation sequences. Copulation itself was brief, lasting 2 to $4 \mathrm{~s}$; and in the four instances when the male called during copulation, he gave mimetic calls. After courtship, song type 11 was given proportionally more often than were other song types (Tables VI, VII), but the differences among song types were not significant, again perhaps due to sample size. The results indicate that song types 18 and 11 are associated with sexual behaviour.

No significant differences were found among song types given at the end of a song bout
(Table V). Song types 1,14 , and chatter each were more likely to initiate a song bout than were song types 11 and 18; they were not significantly different from song type 5 . The results are consistent with the association of chatter and 14 in initiating song bouts upon return from a non-chase. Apparently, both song bouts after an absence from a non-chase situation and song bouts after a period of silence on the call-site begin with the same song types. These song types may be a 'sign-on' for prolonged singing behaviour.

Comfort movements were apparently independent of the song type given before them (Table V). After a comfort movement, however, certain song types were given proportionately more often than others (Table VII). Song type 18 was given significantly more frequently with this behaviour than were 1,14 , mimicry, and chatter, and song type 11 was given significantly more frequently than chatter.

Mimicry was not significantly associated with any single behaviour in the overall analysis, but it was given more often after a behaviour than before (Tables IV and VI). The tendency of mimicry to occur after these behaviours more than before them is significant (binomial test, $P<0.0001)$ for each behaviour. The association of mimetic song with the completion of a behaviour is consistent with a motivational view of mimicry as 'contentment'. It is also consistent with a message interpretation of song - a male that has just sung mimicry may be unlikely to initiate an aggressive act, and a non-aggression message might aid in attracting a female.

A limited series of playback experiments was made in 1973 and 1974 to test whether singing males respond differently to song types. After a male had sung at least 10 songs per min for 2 consecutive min, a series of one of two recorded song types (16 and 1) were broadcast 18 to $20 \mathrm{~m}$ from the call-site, and times and distances of approach and flight of the male and other changes in his behaviour were noted. Details of the experiments are given in Payne \& Payne (1977) with results in terms of male mating success. Males showed no significant differences in their responses to the two song types. The evidence for different behaviour functions of the different song types is thus restricted to the differences in observed behaviours associated with the song in context and not by observing a changed behaviour of other individuals in response. 
Song Structure and Behaviour

The message of animal signals can sometimes be related to the form of the signal. Agonistic visual behaviours often exaggerate the apparent size of a bird and show off the bill or the bend of the wing, structures used as weapons, whereas appeasing behaviours may do the reverse (Darwin 1873; Tinbergen 1959; Smith 1977). In vocal signals no comparable trends are known to explain signal differences. Morton (1977) suggests that low-pitched, harsh animal sounds may generally be used for aggressive signals; and high-pitched, whistled sounds may be used for affinitive, appeasing, or fearful signals. Comparison of song types and the behaviour associated with them suggests some correlates of form and message in the indigobirds.

Particular aspects of the structure of song may recur consistently in different song types with the same messages about behaviour. To test whether certain aspects of song may encode the messages about behaviour, audiospectrograms were compared for common features in song types given in similar circumstances. The four song types (chatter, 1, 18, 11) associated with aggressive or sexual behaviour all begin with chatter notes. All other song types begin with a note or notes mimicking the alarm call of the firefinch host. Among the four song types beginning with a chatter, song structure varies, with chatter being a sequence of similar or identical chatter notes; song type 18 a long sequence of similar chatter notes followed by more buzzy notes; 11 a series of long chatters, then shorter chatters followed by more complex notes that all change rapidly in pitch; and 1 a series of dissimilar buzzy notes.

It is possible to predict behaviour differences among song types from their structure. In the complex song repertoire of the indigobirds there is a tendency for the songs associated with chase and attack to be low-pitched, buzzy sounds as hypothesized by Morton (1977). The structurally antithetical signals, the whistled mimetic songs, are not associated with attack. The combination of chattery notes and whistles in the songs in sexual contexts suggests a compromise in the form of a signal that retains both aggressive and affinitive components.

\section{Sequence of Songs}

The sequences of song types allow several tests of the biological significance of song. Nonrandom association of behaviours such as song suggests causation in two ways (Slater 1973).
First, behaviours that follow one another may depend on a common motivational state of the animal. Second, they may result from a common environmental change that is independent of the preceding state of the animal. Tinbergen (1951) noted that behaviours may be grouped because they are aroused by the same environmental stimuli, but interpretation of these behaviours in terms of internal control has persisted, as discussed by Hinde (1970) and Slater (1973). A descriptive approach is possible using independent measures of the association of song with other behaviour. Behavioural sequences also may provide data with which to test alternative hypotheses about the significance of large repertoires, particularly individual recognition (do sequences differ among individuals and thus form a possible basis for recognition by the mate?); increasing the alertness of other birds, the 'monotony threshold' hypothesis of Hartshorne (1956) (is song sequence unpredictable or determinate?); and the message model (are songs with similar functions associated in sequence?). No obvious predictions are available that would allow a mutually exclusive test of sequence of this 'message' model and the motivational model.

Sequences of at least 100 songs were audiospectrographed for 14 birds. In all 14 birds, each song type was repeated (except for five birds that did not repeat song type 16, two that did not repeat 1 , one that did not repeat 6 , and one that did not repeat 11 or 17 , all probably results of the small sample of songs recorded), and all 14 birds alternated song types 14 and 17 and also alternated 4 and 5 . The small sample size for each male precludes statistical testing for possible sequence differences among individuals, but no differences are obvious in the 14 individual transition tables. Song sequence data were pooled for analysis for all local males.

Each song is likely to be followed by another of the same song type. Runs or repetitions of up to 10 identical songs were noted particularly for mimicry, chatter, and 1; shorter runs of two to five songs were more common for all song types. If all song types had a common 'drive' or were controlled by separate but equal sources of causation (Lemon \& Chatfield 1971; Nelson 1973), one might expect equal lengths of song runs for each song type. Chatter and mimicry were not included in the analysis because these songs often run together for several seconds, and units are more difficult to recognize than in the other song types. When the other song types 
Table VIII. Runs: Number of Songs Repeated in Sequence

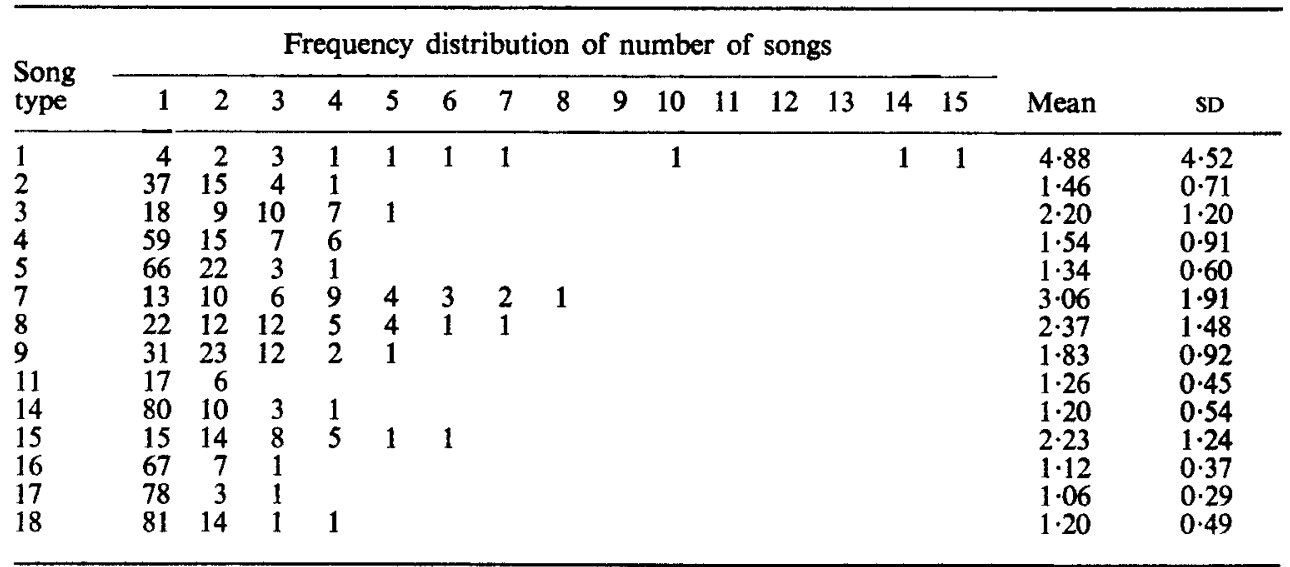

are compared (Table VIII), mean run length varies significantly $(F=29.5, d f=13, P<$ $0.0001)$. The prediction of common or equal causality thus is contradicted by the indigobird song data. Song type 1 has a significantly larger mean run length than any other song type $(F \geqslant 71.4, P<0.0001)$. Chatter, also heard in aggressive contexts, also is often repeated.

Song sequences were examined by analysis of a first-order transition matrix between song types (Table IX). To test whether a song type is given independently of the preceding song type, the table was tested for overall independence. The results (log likelihood-ratio test, $z=10623$, $\chi^{2}=19012, d f=225, P<0.0001$ for both tests) show that song types are not equally likely to follow the preceding song type. Songtype sequence in the indigobirds thus is relatively determinate.

Simultaneous confidence interval tests were applied to each song type (rows) to test whether the next song type was equally likely, given the overall proportion of each song type in the sample. The results are summarized in Table IX. Several general features of song sequence are apparent. (1) Song types are likely to be followed by the same song type (significant for all song types except 16 and 17). Also, several song types are significantly more likely to follow another song of the same song type than they are any other song type $(P<0.05$, Goodman simultaneous confidence interval test, for song types 18 , mimicry, 15, 8, 9, 7, and 3). (2) Several song types tend to alternate: 14 and 17 alternate significantly more often than either repeats, 16 is followed by 2 (and 2 by 16, though this is not the strongest association of a song type after song 2) and 5 by 4 (and reciprocally 4 by 5 , though this association is not significantly greater than the frequency of repetition of 4 by 4). (3) No chaining or determinate sequencing of different song types is evident. Except for the sequence 14-17-4, which often introduces a new bout of singing, and the sequences involving $18,11,1$, and chatter or mimicry, which often involve sexual and aggressive behaviour, no sequential triads appear. The determinacies in indigobird song then appear to involve mainly repetitions, linear pairs, and alternations of pairs and song types, but not long regular sequences.

Of song types that were associated with behavioural transitions, the songs associated with the same behaviours were associated with each other in sequence: chatter and 1 (aggressive behaviour) and 18 and 11 (sexual behaviour) (Table IX). These song types also were in part associated in sequence with each other (chatter with 11 and 18). Mimicry tended to follow 18 , and it may by association be involved in sexual behaviour. Table IX also shows that chatter tends to follow several song types. The association in sequence of chatter with these song types suggests that they all may be related to aggressive signalling. Perhaps the long sequences of songs given by males in territorial advertisement are punctuated by exclamation of this aggressive song.

Kroodsma (1975) and Verner (1976) have suggested that song sequence may be determined by song structure, and they used this prediction as a test of Hartshorne's (1956) monotony threshold hypothesis. If birds order the song sequence so that sequential songs 
ANIMAL BEHAVIOUR, 27, 4

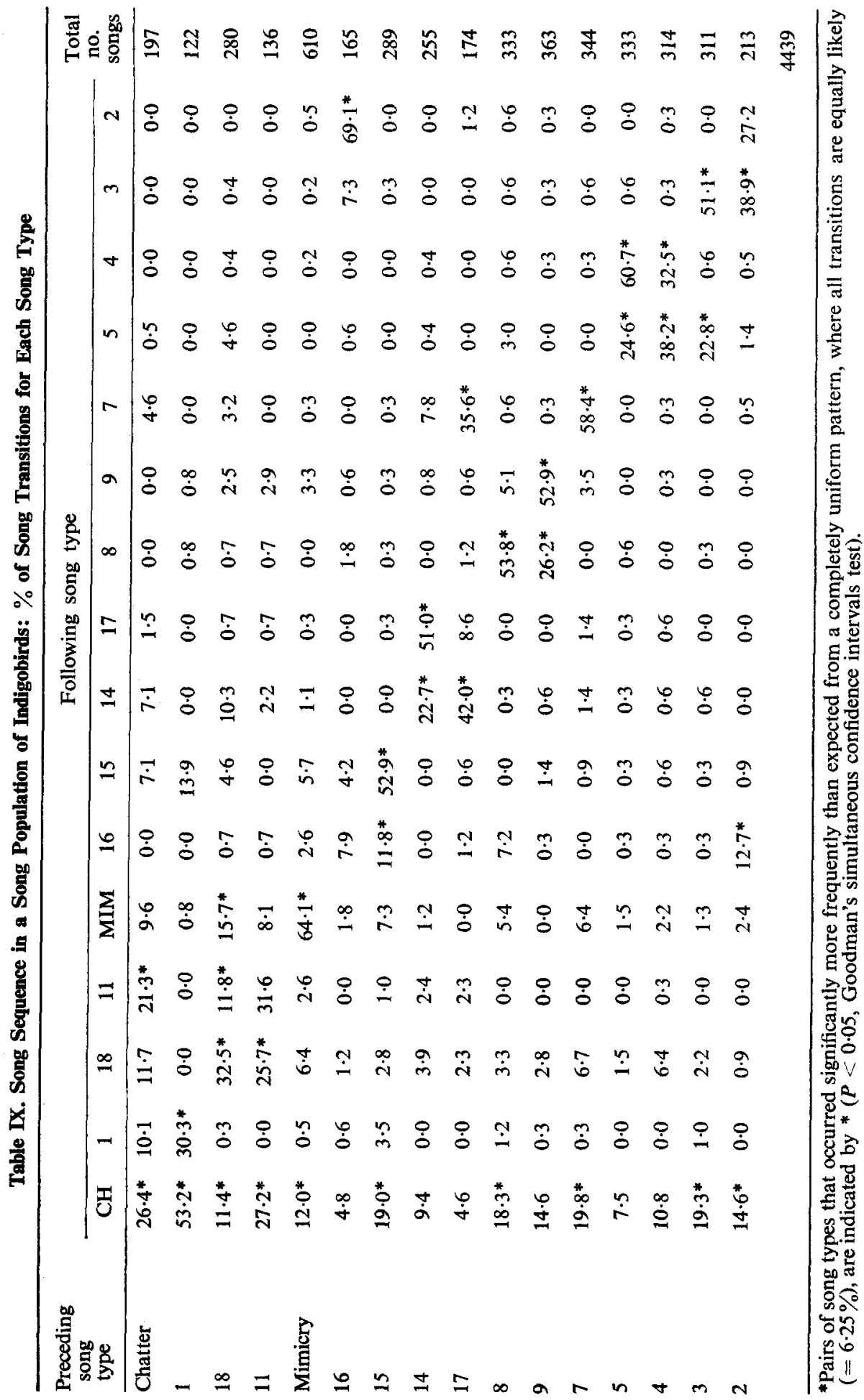


contrast in structure, then the neighbouring birds might be less likely to habituate and so be more likely to avoid the singer's territory. The monotony threshold hypothesis predicts that sequential song types should be less similar in structure than non-sequential song types. This hypothesis was tested for all song types using each of the 19 song characters (Table II). Differences (absolute scores) in the character values were computed for all 120 possible pairs of songs (excluding repetitions of the same song type), and the differences were compared for the 20 song type pairs that were significantly associated (cf. Table IX) with the 100 song type pairs that were not significantly associated. The mean differences were significantly less for the sequence-associated song type pairs for six song characters $(4,5,9,10,12,18)$ than for the non-associated song type pairs $(P<0.05,1$ tailed, Mann-Whitney $U$ test). No significant differences were found for the other 14 song characters $(P>0.05$, 1-tailed, Mann-Whitney $U$ test). None of the 19 song characters examined pointed to a contrast in sound structure for the sequential pairs of songs; short songs did not generally follow long songs, and songs with many notes did not follow songs with few notes. Analysis of the difference between song characters of associated pairs of song types and other pairs of song types fails to support the monotony threshold hypothesis for any character and allows us to reject it for several song characters.

If the monotony threshold hypothesis is appropriate, we might also predict that the average difference in song structure as determined by phenetic distance is greater for songs that have a high tendency to follow one another than for songs with no such tendency. Correlation tests were performed on standardized song characters for all pairs of songs and the phenetic distances $D$, where $D=1-r_{\mathrm{p}}$, were read from the resulting distance matrix. Excluding repetitions of the same song type, the 20 dyadic pairs of song types that were significantly associated with each other (Table IX) were not significantly more different in structure than were all other pairs of song types (MannWhitney $U=922, P=0.58,1$-tailed). Hence the sequence of songs is more closely predicted by the hypothesis that the various song types have different but overlapping messages than by the 'monotony avoidance' hypothesis.

\section{Discussion}

Several song types of the indigobirds are associated with different behaviours and appear to signal the likelihood of the behaviour of the male. Different song types were statistically not independent of these behaviours. Two song types are associated with intraspecific aggressive behaviour among males and two others are given in sexual contexts. Three song types are given in initiating a song bout after a period of silence on the call-site, and two of these plus another are used upon returning to the call-site after other acts are completed. The behavioural messages of certain song types appear to overlap, much as visual displays may have multiple functions (Beer 1975; McKinney 1975). This appears to be the first known example of such a large bird-song repertoire involving several distinct song types where a large proportion of the song types have different behavioural 'messages' in the sense of associated behaviours of the singing individual (Smith 1977). The different messages may be associated with the structure of song, particularly by the common chatter notes that precede song types with aggressive or sexual messages, and by their absence in other song types.

Song types that were given before an aggressive behaviour were the same ones that were given after an intrasexual aggressive behaviour (song types 1 and chatter). Similarly, one song type (11) was given both before a sexual interaction (attracting female and attempting to mount her) and after a courtship attempt. These results suggest that the 'message' interpretation of the association between the song and the behaviour that follows the song, using 'message' in the sense of Smith (1977), may be subsumed in the more general 'motivation' interpretation of the association. However, this interpretation is complicated by the possibility of repeated sequences of acts: a male singing an aggressive song after an aggressive act may signal that it will chase again if an intruding male reappears in the area. Further work will be required to determine the usefulness of 'message' analysis (Smith 1977).

Song repertoire size may be explained also in terms of sexual selection, with females choosing males on the basis of their number of songs (Howard 1974; Kroodsma 1976b; Krebs 1977) or intrasexual selection by males that avoid the territories of other males with more songs (Bertram 1970; Howard 1974; Dobson \& Lemon 1975; Kroodsma 1976a; Krebs 1976). Predictions of these models of sexual selection for song repertoire can be tested in the indigobirds. 


\section{Intersexual Selection}

Intersexual selection by female preference for males with larger song repertoires might be supported by two kinds of observations: (1) Males with more songs gain more matings and produce more young than males with fewer songs. (2) Males sing during mate choice and sexual behaviour.

These predictions are not strongly supported by field observations. (1) Although males vary greatly in mating success, the song differences among local males are minor variants of syllable form or number, not repertoire size. (2) Females visit different males before mating, and they visit repeatedly around the song neighbourhood throughout the breeding season. Visits to the call-site often last 2 to $3 \mathrm{~min}$, long enough for a female to sample a male's song repertoire. Female mate choice, shown by visiting rates to different males and number of matings with each male, is correlated with the time each male spends singing (Payne \& Payne 1977). But though singing behaviour seems important in female mate choice and male mating success, the qualitative song differences among males are minor (Table I, Fig. 2), and the quantitative differences are explained by time spent singing and not by any differences among males in repertoire or proportions of song types. Female mate selection may involve repertoire size in some bird species, as song repertoire size is higher in the more polygynous species of wrens (Kroodsma 1977), and the ovarian responses of domesticated canaries are greater to recorded playbacks of males with larger song repertoires (Kroodsma 1976b). Howard (1974) showed that male mockingbirds (Mimus polyglottos) with larger repertoires mated earlier but also had apparently better territories, suggesting that song differences were effective mainly through male territorial behaviour. In the indigobirds, song is given before the female flies to the male, but song is often omitted in successful copulation sequences, and the male does not sing through his repertoire after the female arrives on his call-site, but instead she solicits at once. These observations suggest that Darwinian intrasexual selection provides no more than an indirect explanation of repertoire size.

Sexual selection in song behaviour (but not directly in repertoire size) in indigobirds is suggested by the structure of the songs used in sexual and in aggressive circumstances. The sexual songs (18 and 11) have structural features (introductory chatter notes) in common with the aggressive song types (chatter and 1), and they are associated with behaviour involving female approach to the call-site (females visit the sites mainly when the male sings either one of the aggressive song types or the sexual song type most similar in auditory structure to these songs). In addition these songs tend to occur together in sequence. The association of sexual and aggressive behaviours in indigobird song parallels the visual displays of the birds, as courtship display is structurally similar to the behaviour directed toward intruding male competitors. Similar sexual behaviour resembling the male-male aggressive behaviour in form also occurs in some other polygynous birds in which no pair bond is maintained between the sexes (Payne \& Payne 1977). The results suggest that song as well as visual displays have evolved as a result of females choosing as mates the more aggressive males that display their competence in intrasexual aggressive behaviour in the presence of the females as well. Darwinian sexual selection in these birds may result for the greatest part through the process of male-male intrasexual competition.

\section{Intrasexual Selection}

Three models that might explain the success of a male with a large song repertoire in maintaining a territory have been summarized by Krebs (1977). (1) Males with larger repertoires may successfully countersing with other neighbouring males, as the song types will match those of the neighbours. Several species of songbirds with large repertoires match their song types when they countersing in apparent territorial contest (Lemon 1968; Verner 1976). But, as Krebs suggests, the number of songs often is larger than the number of neighbours, so repertoire size is not explained simply by countersinging. (2) Males with larger repertoires may avoid habituation of their neighbours. The decreased responsiveness of territorial males to playbacks of song types of their neighbours (Weeden \& Falls 1959; Falls 1969; Goldman 1973; Emlen 1971; Petrinovich \& Peeke 1973; Brooks \& Falls 1975) compared to their responsiveness to the songs that they have not heard repeatedly in the season provide evidence for male- and song-specific habituation. Hartshorne (1956) and Dobson \& Lemon (1975) suggested that large repertoires may function to decrease habituation of neighbours; but as Verner (1976) and Krebs (1977) point out, one must then explain the adaptive significance 
of song habituation. (3) Males with larger song repertoires may decrease the number of new males attempting to establish territories in their area, if the males without territories avoid areas of apparent high population density (Krebs 1977). However, the assumption (Fretwell \& Lucas 1969) that birds select a habitat largely in response to population density has not been confirmed in any field studies. Also, as Krebs points out, 'faking' a high density implies that competing males could readily be deceived, but it seems likely that such 'cheating' would rapidly be selected against through the success of birds that disregard such false advertising.

These three suggested models, whereby a male with a larger-than-average number of song types may have an advantage over other males, lead to several testable predictions, not all mutually exclusive. (a) Song function as indicated by context should be mainly intrasexual, particularly in male-male territorial interactions (models $1,2,3$ ). (b) The number of song types should vary among males in a local population, and the breeding success of males should be directly related to the number of their song types (models 1, 2, 3). (c) Males should match song types in countersinging on neighbouring territories (model 1). (d) Individual males should sing identical songs from year to year to aid in long-term individual recognition by neighbours, who would avoid their territories (model 2).

(e) The sequence of song types should be unpredictable, as randomness would minimize habituation by neighbouring males (model 2). (f) The sequence of song types should be such that the contrast between successive songs is high (models 2,3 ). (g) Males should visit widely over a local area and should sample the songs of the singing territorial males (model 3).

(a) Most behaviour contexts that involve another individual interacting with the singing male were male-male agonistic interactions (Table IV); few involved male-female interactions. Interspecific interactions with the firefinch host were even less frequent. A firefinch visited the male indigobird only seven times in the observations, though when it did, it visited as the male indigobird was mimicking the firefinch song. Indigobirds do not use a firefinch response to vocal mimicry in their nestfinding behaviour or in laying; females are silent and travel alone (Payne 1973). Song mimicry probably is adaptive in advertising the species of host that successfully reared the male, who learns the song from the foster parent, to females with a similar upbringing, and is a result of sexual selection through mate choice by the female (Payne 1973; Sullivan 1976). Association of song with male-male agonistic behaviour and the persistent singing on a call-site defended against intruding males (Payne \& Payne 1977) are consistent with the view that song is largely directed toward advertising a territory and excluding other males. The results are consistent with models 1,2 and 3.

(b) Song repertoires are identical or nearly so among all males in a local population, in the song population described here, in other marked populations in the Lochinvar area, and in other populations that I have sampled in Zambia, Rhodesia, Malawi, and South Africa. In the marked population at Lochinvar, the variation in breeding success among the males is high, yet all have the same number of song types. The results are inconsistent with the prediction of variation in models 1,2 and 3 .

(c) Neighbouring males sometimes countersing with matching song types, as documented by simultaneous tape recordings of two pairs of males on sites located within $100 \mathrm{~m}$ of each other at Lochinvar, and by recordings at other localities (Payne 1973). In part, matching may result from the tendency of certain song types to follow each other in sequence, with one song type entraining the sequence of the responding bird. Countersinging and matching song types suggest that part of the function of song is directed toward neighbouring singing males rather than intruding males with no local callsite, and the density-assessment hypothesis does not explain this context of song. Countersinging is, however, uncommon, as most singing males are out of hearing of each other (Payne \& Payne 1977); hence countersinging (model 1) does not explain song repertoire size.

(d) Although each marked male indigobird followed for two to four years in the wild generally kept the same song types from year to year, each song type changed slightly, and the cumulative changes made it difficult to match some song types across a gap of years. Yearly changes are probably explained in part by each male copying the minor individual variations in song of the most successful breeding male (Payne in press). The yearly changes as well as the fact that all neighbouring males generally share all their song types indicate that the song types are not involved in individual recognition in the way suggested by Krebs (1977); rather the males all may mimic the most 
successful local individual. The results are inconsistent with model 2.

(e) Song sequence in indigobirds is not random. The determinism in sequence contradicts the idea (model 2) that repertoire size is important in avoidance of song habituation by neighbouring males.

(f) Sequence of song types is not closely related to the structure of the songs in a way suggesting contrast of successive songs. The overall structural differences between song types associated in sequence are no greater than the difference between songs not regularly given in sequence, and all song types tend to be repeated. The results contradict the prediction from models 2 and 3 .

(g) Males visit each other over an area of about $10 \mathrm{~km}^{2}$ in a song population, but the circumstance of visits does not suggest density assessment by non-territorial males searching for a suitable habitat. Intruders at each call-site often are males that already have a call-site but little or no mating success. Traditional sites where mating success is high tend to be visited more frequently and by more males than sites where mating success is low. When a good site becomes available through the disappearance of the resident male, it is readily occupied; sites with no mating success are not (Payne \& Payne 1977). Male visiting occurs throughout the breeding season, not just during initial territorial establishment as in the densityassessment model, i.e. model 3. The visiting pattern among male indigobirds is more directly explained by competition for the traditional best call-sites than by density assessment.

In summary the observed song behaviour of the indigobirds provides limited support for the models of adaptive function of large song repertoires, but the results contradict a number of specific predictions based on countersinging, avoidance of habituation of other males, or density assessment. On the other hand the number of songs is in part explained by the adaptive significance of signalling the subsequent behaviour of the singing bird.

\section{Acknowledgments}

Observations and tape recordings at Lochinvar National Park were permitted by the Department of Wildlife and National Parks, Chilanga, Zambia, and I am grateful for facilities provided by the Department. Dale Lewis and Karen Payne helped to tape-record and observe birds in the field. For assistance with audiospectro- grams I thank Steve Hinshaw, Diane Humes, Jan Peugh, Deborah Trowbridge, Deborah Turrell, and Karen Wilson. Kent Fiala, Ken Guire, and William Ericson advised on or carried out the statistical analyses. For critical comments on the manuscript I thank Luis Baptista, William Ericson, Brian Hazlett, Don Kroodsma, Ross Lein, W. John Smith, Bill Thompson, and Jerry Verner. Work was supported by NSF grants GB29017X and BMS75-03913.

\section{R E F E R E N C E S}

Altmann, J. 1974. Observational study of behavior: sampling methods. Behaviour, 49, 227-267.

Baptista, L. F. 1978. Territorial, courtship and duet songs of the Cuban Grassquit (Tiaris canora). $J$. Ornithol., 119, 91-101.

Beer, C. G. 1975. Multiple functions and gull displays. In: Function and Evolution in Behaviour (Ed. by G. Baerends, C. Beer \& A. Manning), pp. 16-54. Oxford: Clarendon Press.

Bertram, B. 1970 . The vocal behaviour of the Indian hill mynah, Gracula religiosa. Anim. Behav. Monogr., 3, 79-192.

Brooks, R. J. \& Falls, J. B. 1975. Individual recognition by song in white-throated sparrows. I. discrimination of songs of neighbours and strangers. Can. $J$. Zool., 53, 879-892.

Darwin, C. 1873. The Expression of the Emotions in Man and Animals. London: D. Appleton.

Dobson, D. W. \& Lemon, R. E. 1975. Re-examination of monotony threshold hypothesis in bird song. Nature, Lond., 257, 126-128.

Emlen, S. T. 1971. The role of song in individual recognition in the indigo bunting. $Z$. Tierpsychol., 28, 241-246.

Falls, J. B. 1969. Functions of territorial song in the white-throated sparrow. In: Bird Vocalizations (Ed. by R. A. Hinde), pp. 207-232. Cambridge: Cambridge University Press.

Fretwell, S. D. \& Lucas, H. L. 1969. On territorial behaviour and other factors influencing habitat distribution in birds. Acta Biotheoretica, 19, 16-36.

Goldman, P. 1973. Song recognition by field sparrows. Auk, 90, 106-113.

Goodman, L. A. 1964. Simultaneous confidence intervals for contrasts among multinomial proportions. Ann. Math. Stat., 35, 716-725.

Hartshorne, C. 1956. The monotony threshold in singing birds. Auk, 73, 176-192.

Hinde, R. A. 1970. Animal Behaviour. New York: McGraw-Hill.

Howard, R. D. 1974. The influence of sexual selection and interspecific competition on mockingbird song (Mimus polyglottos). Evolution, 28, 428438.

Immelmann, K. 1968. Zur biologischen Bedeutung des Estrildidengesanges. J. Ornithol., 109, 284-299.

Krebs, J. R. 1976. Bird song and territory defence. New Scientist, 70, 534-536.

Krebs, J. R. 1977. The significance of song repertoires: the Beau Geste hypothesis. Anim. Behav., 25, $475-478$. 
Kroodsma, D. E. 1975. Song patterning in the rock wren. Condor, 77, 294-303.

Kroodsma, D. E. 1976a. The effect of large song repertoires on neighbor 'recognition' in male song sparrows. Condor, 77, 97-99.

Kroodsma, D. E. 1976b. Reproductive development in a female songbird: differential stimulation by quality of male song. Science, $N$. Y., 192, 574-575.

Kroodsma, D. E. 1977. Correlates of song organization among North American wrens. Am. Nat., 111, 995-1008.

Lein, M. R. 1972. Territorial and courtship songs of birds. Nature, Lond., 237, 48-49.

Lein, M. R. 1978. Song variation in a population of chestnut-sided warblers (Dendroica pensylvanica): its nature and suggested significance. Can.J.Zool., 56, 1266-1283.

Lemon, R. E. 1968 . The relation between organization and function of song in cardinals. Behaviour, 32, 158-178.

Lemon, R. E. \& Chatfield, C. 1971. Organization of song in cardinals. Anim. Behav., 19, 1-17.

Marler, P. 1969. Tonal quality of bird sounds. In: Bird Vocalizations (Ed. by R. A. Hinde), pp. 5-18. Cambridge: Cambridge University Press.

McKinney, F. 1975. The evolution of duck displays. In: Function and Evolution in Behaviour (Ed. by G. Baerends, C. Beer \& A. Manning), pp. 331357. Oxford: Clarendon Press.

Morse, D. 1970. Territorial and courtship songs of birds. Nature, Lond., 226, 659-661.

Morton, E. S. 1977. On the occurrence and significance of motivation-structural rules in some bird and mammal sounds. Am. Nat., 111, 855-869.

Nelson, K. 1973. Does the holistic study of behavior have a future? In: Perspectives in Ethology (Ed. by P. P. G. Bateson \& P. H. Klopfer), pp. 281328. New York: Plenum Press.

Payne, R. B. 1973. Behavior, mimetic songs and song dialects, and relationships of the parasitic indigobirds (Vidua) of Africa. Ornithol. Monogr., 11, 1-333.

Payne, R. B. In press. Population structure and social behavior: models for testing the ecological significance of song dialects in birds. In: Natural selection and social behavior: recent research and new theory. (Ed. by R. D. Alexander \& D. W. Tinkle). New York: Chiron Press.
Payne, R. B. \& Payne, K. 1977. Social organization and mating success in local song populations of village indigobirds, Vidua chalybeata. Z. Tierpsychol., 45, 113-173.

Petrinovich, L. \& Peeke, H. V. S. 1973. Habituation to territorial song in the white-crowned sparrow (Zonotrichia leucophrys). Behav. Biol., 8, 743-748.

Slater, P. J. B. 1973. Describing sequences of behaviour. In: Perspectives in Ethology (Ed. by P. P. G. Bateson \& P. H. Klopfer), pp. 131-153. New York: Plenum Press.

Smith, R. L. 1959. The songs of the grasshopper sparrow. Wilson Bull., 71, 141-152.

Smith, W. J. 1969. Messages of vertebrate communication. Science, $N . Y$., 165, 145-150.

Smith, W. J. 1977. The Behavior of Communicating: An Ethological Approach. Cambridge, Mass.: Harvard University Press.

Sneath, P. H. A. \& Sokal, R. R. 1973. Numerical Taxonomy. San Francisco: Freeman.

Sokal, R. R. \& Rohlf, F. J. 1969. Biometry. San Francisco: Freeman.

Sullivan, G. A. 1976. Song of the finch Lagonosticta senegala: interspecific mimicry by its broodparasite Vidua chalybeata and the role of song in the host's social context. Anim. Behav., 24, 880-888.

Thielcke, G. 1970. Die sozialen Funktionen der Vogelstimmen. Vogelwarte, 25, 204-229.

Thielcke, G. \& Thielcke, H. 1970. Die sozialen Funktionen verschiedener Gesangsformen des Sonnenvogels (Leiothrix lutea). Z. Tierpsychol., 27, 177185.

Tinbergen, N. 1951. The Study of Instinct. Oxford: Oxford University Press.

Tinbergen, N. 1959. Comparative studies of the behaviour of gulls (Laridae): a progress report. Behaviour, 15, 1-70.

Verner, J. 1976. Complex song repertoire of male longbilled marsh wrens in eastern Washington. Living Bird, 14, 263-300.

Weeden, J.'S. \& Falls, J. B. 1959. Differential responses of male ovenbirds to recorded songs of neighboring and more distant individuals. $A u k, 76$, 343-351.

(Received 16 January 1978; revised 8 November 1978; MS. number: A2130) 